\section{(6) OPEN ACCESS}

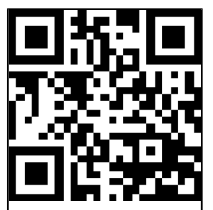

Open Access Scan to access mo free content

- Additional material is published online only. To view please visit the journal online (http://dx.doi.org/10.1136/ thoraxjnl-2013-203600).

${ }^{1}$ Department of Medicine, University of Cape Town, Cape Town, South Africa ${ }^{2}$ Michael G DeGroote School of Medicine, McMaster University, Hamilton, Canada ${ }^{3}$ Department of Medicine, University of Wisconsin, Madison, Wisconsin, USA ${ }^{4}$ Krefting Research Centre, University of Gothenburg, Gothenburg, Sweden ${ }^{5}$ Center for Genomics and Personalized Medicine, Wake Forest School of Medicine, Winston-Salem, North Carolina, USA

${ }^{6}$ Respiratory Medicines Development Center, GlaxoSmithKline,

Raleigh-Durham, North Carolina, USA

${ }^{7}$ Respiratory Medicines Development Centre, GlaxoSmithKline, Uxbridge, UK ${ }^{8}$ Quantitative Sciences Division, GlaxoSmithKline, Uxbridge, UK ${ }^{9}$ Institute of Inflammation and Repair, University of

Manchester, University Hospital of South Manchester,

Manchester, UK

\section{Correspondence to} Dr Eric D Bateman, Division of Pulmonology, Department of Medicine, University of Cape Town, Anzio Road, Observatory, Cape Town 7937, South Africa; Eric.Bateman@uct.ac.za

Received 19 March 2013 Revised 28 October 2013 Accepted 31 October 2013 Published Online First 19 November 2013

To cite: Bateman ED, O'Byrne PM, Busse WW, et al. Thorax 2014;69: 312-319.

\title{
Once-daily fluticasone furoate (FF)/vilanterol reduces risk of severe exacerbations in asthma versus FF alone
}

\author{
Eric D Bateman, ${ }^{1}$ Paul M O'Byrne, ${ }^{2}$ William W Busse, ${ }^{3}$ Jan Lötvall, ${ }^{4}$ \\ Eugene R Bleecker, ${ }^{5}$ Leslie Andersen, ${ }^{6}$ Loretta Jacques, ${ }^{7}$ Lucy Frith, ${ }^{8}$ \\ Jessica Lim, ${ }^{8}$ Ashley Woodcock ${ }^{9}$
}

\begin{abstract}
Background Combination therapy with an inhaled corticosteroid (ICS) and long-acting $\beta_{2}$ agonist (LABA) is recommended for patients with asthma symptomatic on ICS alone. However, there is ongoing debate regarding the risk-benefit ratio of using LABA in asthma.

Objective To evaluate the effect of the addition of a novel LABA, vilanterol $(\mathrm{VI})$, to a once-daily ICS,

fluticasone furoate (FF), on the risk of severe asthma exacerbations in patients with uncontrolled asthma.

Methods This randomised double-blind comparative study of variable duration ( $\geq 24-78$ weeks) was designed to finish after 330 events (each patient's first ontreatment severe asthma exacerbation). 2019 patients with asthma aged $\geq 12$ years with $\geq 1$ recorded exacerbation within 1 year were randomised and received FF/VI $100 / 25 \mu \mathrm{g}$ or FF $100 \mu \mathrm{g}$, administered once daily in the evening. The primary endpoint was time to first severe exacerbation; secondary endpoints were rate of severe asthma exacerbations per patient per year and change in trough evening forced expiratory volume in $1 \mathrm{~s}\left(\mathrm{FEV}_{1}\right)$ from baseline.
\end{abstract}

Results Compared with FF, FF/VI delayed the time to first severe exacerbation (HR $0.795,95 \% \mathrm{Cl} 0.642$ to 0.985 ) and reduced the annualised rate of severe exacerbations (rate reduction $25 \%, 95 \% \mathrm{Cl} 5 \%$ to $40 \%$ ). Significantly greater improvements in trough $\mathrm{FEV}_{1}$ $(p<0.001)$ were observed with FF/VI than with FF at weeks 12, 36, 52 and at endpoint. Both treatments were well tolerated with similar rates of treatmentrelated adverse events and on-treatment serious adverse events.

Conclusions Once-daily FF/VI reduced the risk of severe asthma exacerbations and improved lung function compared with FF alone, with good tolerability and safety profile in adolescents and adults with asthma currently receiving ICS.

\section{ClinicalTrials.gov No NCT01086384}

\section{INTRODUCTION}

The addition of a long-acting $\beta_{2}$ agonist (LABA) to an inhaled corticosteroid (ICS) is recommended for patients whose asthma is inadequately controlled on medium-dose ICS. ${ }^{1}$ This has been shown to improve both pulmonary function and asthma control and to reduce the risk of exacerbations, ${ }^{2}{ }^{3}$ and is the most effective and preferred option for patients requiring a step-up in asthma controller therapy, at least in

\section{Key messages}

What is the key question?

- Does the new once-daily ICS/LABA combination $\mathrm{FF} / \mathrm{VI}$ reduce the risk of severe asthma exacerbations compared with ICS alone?

What is the bottom line?

- This randomised double-blind comparative study in patients with asthma uncontrolled on ICS confirms that the combination of FF $100 \mu \mathrm{g}$ plus VI $25 \mu \mathrm{g}$ reduces the risk of severe exacerbations compared with FF $100 \mu \mathrm{g}$ alone.

\section{Why read on?}

- This study, which employed a unique event-driven design to ensure sufficient power to study exacerbation frequency and in which most patients received treatments for $>1$ year, confirmed that $\mathrm{FF} / \mathrm{VI}$ with its once-daily dosing regimen is more effective in reducing exacerbation risk in uncontrolled asthma than FF alone.

adolescents and adults. However, although almost all studies have confirmed that the addition of a LABA reduces asthma exacerbations, controversy has arisen around data from a large-scale safety study ${ }^{4}$ and meta-analyses ${ }^{5} 6$ suggesting that more severe and lifethreatening asthma events and even deaths may be increased in patients receiving LABAs. A possible explanation for this apparent increase in risk is the failure of patients being treated with LABA to receive concurrent ICS treatment. ${ }^{4} 7$ Indeed, this has been supported by meta-analyses comparing ICS/LABA administered as concurrent treatment (rather than from separate inhalers) with ICS alone. ${ }^{6}{ }^{8}$ Nonetheless, this concern has resulted in reassessment of the benefits and costs of combined treatment with LABA and ICS, whether as mono-components or in combination inhalers, and for studies to examine more closely rare severe life-threatening asthma exacerbations. ${ }^{9}$ Thus, large prospective safety trials of currently marketed LABAs are underway internationally.

A new ICS/LABA combination currently being evaluated for use in asthma and chronic obstructive 
pulmonary disease contains fluticasone furoate (FF) and vilanterol (VI). FF is a novel ICS structurally distinct from fluticasone propionate (FP), with an ester derived from 2-furoic acid at the $\mathrm{C}-17 \alpha$ position that replaces the simpler propionate ester, ${ }^{10}$ conferring both greater affinity for the GC receptor and longer retention in respiratory tissues than $\mathrm{FP}^{11}$ Once-daily FF has been shown to be effective in phase IIb trials, ${ }^{12-14}$ and the FF dose used in this study was selected on the basis of data from these studies. VI is a once-daily inhaled LABA shown to produce prolonged bronchodilation for at least $24 \mathrm{~h}$. Previous clinical studies of FF/VI delivered from a single inhaler, conducted in patients with chronic obstructive pulmonary disease and including higher dosages of FF than in the present study, have shown this combination to have an acceptable safety profile. $^{15} 16$

We report here the results of a large study, with exposure of $>1$ year in most patients, examining the benefits and risks of FF $100 \mu \mathrm{g}$ and VI $25 \mu \mathrm{g}$ administered once daily in combination in patients with asthma uncontrolled on ICS or ICS/LABA and who were consequently at increased risk of asthma exacerbations. The primary endpoint was time to first severe asthma exacerbations, as defined by the European Respiratory Society/American Thoracic Society (ERS/ATS) Task Force. ${ }^{17}$ Safety endpoints included asthma events leading to hospitalisation and intubation. Preliminary results have been presented in abstract form. ${ }^{18}$

\section{METHODS}

\section{Patients}

Patients aged $\geq 12$ years were eligible if they had a history of asthma as defined by the National Institutes for Health ${ }^{19}$ for $\geq 1$ year prior to screening, were using ICS at a dose of $\geq 200 \mu \mathrm{g}$ /day FP or equivalent or ICS/LABA at a dose of 200/ $100-500 / 100 \mu \mathrm{g} \mathrm{FP} / \mathrm{salmeterol}$ or equivalent for $\geq 12$ weeks prior to screening and at a stable dose for 4 weeks prior to screening and throughout the run-in period, and had $\geq 1$ asthma exacerbation requiring systemic corticosteroids and/or hospital or emergency room visit in the previous year.

Eligible patients had a best prebronchodilator forced expiratory volume in $1 \mathrm{~s}\left(\mathrm{FEV}_{1}\right)$ of $50-90 \%$ predicted normal at screening, and could demonstrate $\geq 12 \%$ and $\geq 200 \mathrm{~mL}$ reversibility with inhaled salbutamol/albuterol. Patients' ICS therapy was discontinued at randomisation and replaced with study medication. At randomisation, patients were required to have a recorded use of albuterol/salbutamol and/or asthma symptoms on $\geq 3$ of the last 7 consecutive days on their daily diary.

\section{Study design and treatments}

This phase III randomised, multicentre, double-blind, parallel-group study (HZA106837; ClinicalTrials.gov registration number NCT01086384) was conducted at 167 centres in 11 countries between 22 February 2010 and 15 September 2011. After a 2 -week run-in period during which baseline safety evaluations and measures of asthma status were conducted, patients were randomised $(1: 1)$ to one of two treatments administered via the ELLIPTA dry powder inhaler (GlaxoSmithKline). FF/VI 100/25 $\mu \mathrm{g}$ (representing an emitted dose from the dry powder inhaler of $92 \mu \mathrm{g}$ for FF and $22 \mu \mathrm{g}$ for VI) or FF $100 \mu \mathrm{g}$ were administered once daily in the evening for a required minimum of 24 weeks and up to 78 weeks. Patients replaced their current short-acting bronchodilator and used albuterol/salbutamol as-needed for symptoms.

Patients were randomised using an automated interactive telephone-based system (RAMOS; GlaxoSmithKline, UK) in accordance with a computer-generated schedule (RandAll; GlaxoSmithKline, UK). Following randomisation, patients were not permitted to use ICS other than study medication (see online supplementary appendix for a full list of permitted and prohibited medications).

An event-driven design was employed, meaning that the study was planned to finish after 330 'events' had occurred. An event was defined as a patient's first severe asthma exacerbation in the study. A severe asthma exacerbation was defined using the ERS/ ATS Task Force recommendation as a deterioration of asthma requiring the use of systemic corticosteroids for at least 3 days, or inpatient hospitalisation, or emergency department visit due to asthma requiring systemic corticosteroids. ${ }^{17} \mathrm{~A}$ blinded independent adjudication committee ensured that all severe asthma exacerbations were captured as defined in the protocol. Only events deemed by the adjudication committee to be severe asthma exacerbations were used in the endpoint analysis.

One interim analysis was performed to evaluate the primary endpoint (ie, time to first severe asthma exacerbation) and to identify any potential treatment harm by reviewing the most frequent on-treatment adverse events and asthma-related mortality/ morbidity (see online supplementary appendix).

\section{Outcome measurements}

The primary endpoint was time to first severe asthma exacerbation. Secondary efficacy endpoints were rate of severe asthma exacerbations per patient per year and change from baseline at week 36 in evening trough $\mathrm{FEV}_{1}$. Other endpoints are listed in the online supplementary appendix.

\section{Safety}

Safety endpoints relating to severe asthma exacerbations included the number of hospitalisations, emergency department/ urgent care visits, unscheduled healthcare provider visits and intubations for an asthma event. General safety and tolerability endpoints including vital signs were monitored (see online supplementary appendix).

Patients were withdrawn from the study if they experienced three on-treatment severe asthma exacerbations in any 6-month period or four throughout the treatment period.

\section{Statistical analysis}

Three hundred and thirty events were required to provide $90 \%$ power to detect a $30 \%$ reduction in risk (HR 0.70) of severe asthma exacerbation at a two-sided significance level of 0.05 . The total sample size of 2000 (1000 per treatment arm) was based on assumptions of $10 \%$ loss to follow-up, $20 \%$ of patients in the FF arm having $\geq 1$ severe asthma exacerbations per year and a recruitment pattern as specified in the protocol.

The primary efficacy endpoint was analysed by Cox proportional hazards analysis (FF/VI vs FF) of time to first severe asthma exacerbation, incorporating terms for baseline $\mathrm{FEV}_{1}$, sex, age and region. A Cox proportional hazards analysis was performed to examine treatment interactions with these covariates. Statistical methods for the secondary and other efficacy endpoints and sensitivity analyses including the interim analysis of the primary efficacy endpoint are described in the online supplementary appendix. All efficacy and safety analyses were carried out in the intent-to-treat (ITT) population other than those specified as being carried out in the per protocol (PP) population (see online supplementary appendix). The decision to exclude a patient or some of a patient's data from the PP population was made prior to breaking the blinding. 


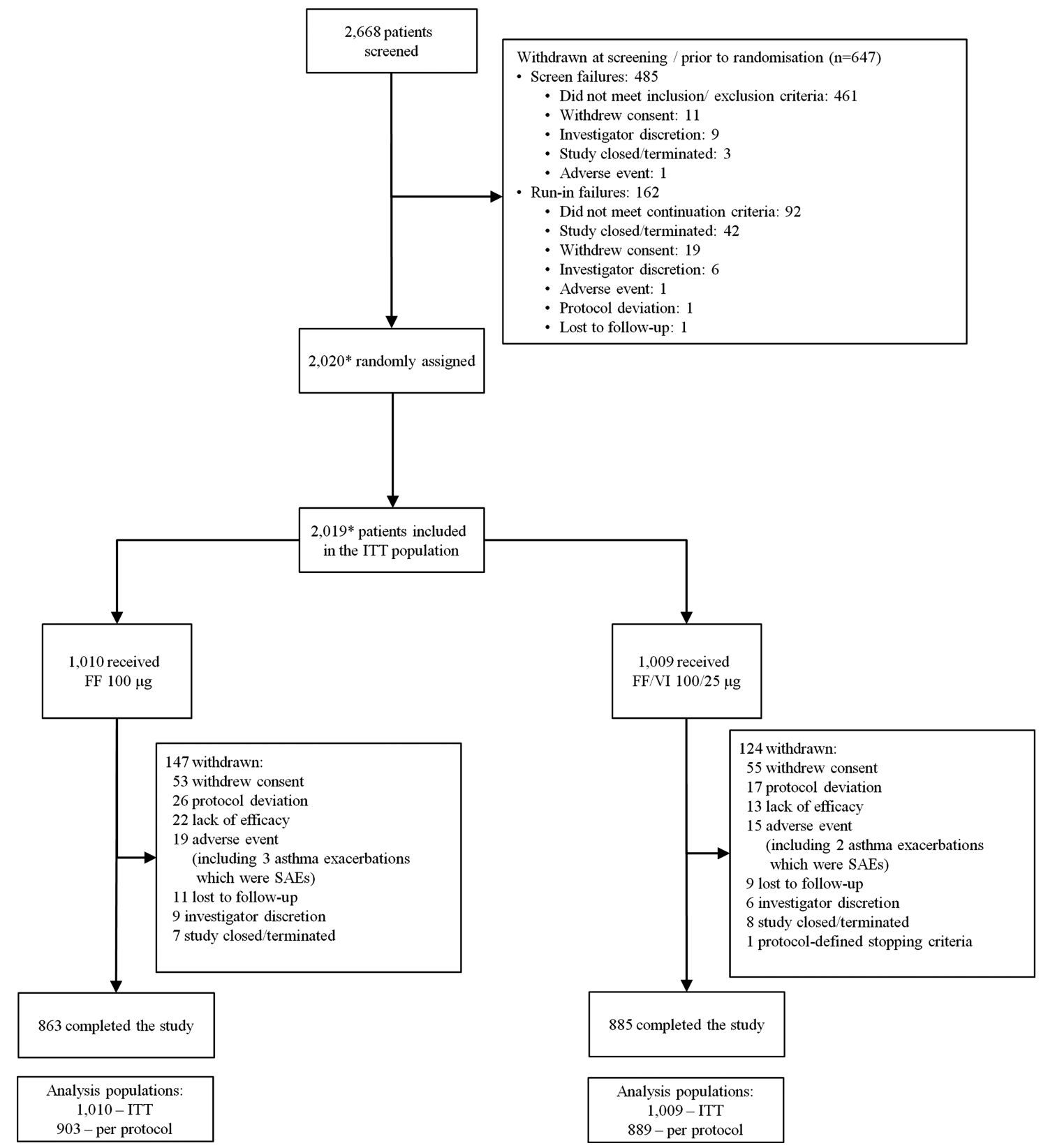

Figure 1 Patient disposition and reasons for withdrawal post-screening. * One patient was not randomised but received $\mathrm{FF} 100 \mu \mathrm{g}$ in error and one patient was randomised but did not receive treatment; these patients are not included in the ITT population. The patient who received FF $100 \mu \mathrm{g}$ in error received 5 days of treatment and then was withdrawn. No safety issues were identified during this treatment period; FF, fluticasone furoate; ITT, intent-to-treat; SAE, severe adverse event; VI, vilanterol.

\section{RESULTS}

Of 2668 patients screened, 2020 were randomised and 2019 comprised the ITT population (figure 1). The PP population consisted of 1792 patients (89\% of the ITT population): 903 received FF $100 \mu \mathrm{g}$ and 889 received FF/VI 100/25 $\mu \mathrm{g}$. Demographics and baseline characteristics were generally similar across the treatment groups in the ITT (table 1 and online supplementary table E1) and PP populations. All patients were taking ICS at baseline and approximately $60 \%$ of patients were also receiving a LABA either as a separate inhaler or as part of an ICS/ LABA combination product. Adolescents (age 12-17 years) comprised $14 \%$ of the ITT population.

Due to the event-driven study design, the duration of exposure to study treatment was variable. A minimum duration of active treatment of 24 weeks was planned; only patients who were either withdrawn by the investigator or withdrew voluntarily had $<24$ weeks of treatment. All patients who completed the planned double-blind treatment period were treated for $\geq 24$ weeks and no patients were treated for longer than 78 weeks. The mean duration of treatment exposure (52.0-52.7 weeks) and the proportion of patients who received treatment for $\geq 52$ weeks $(56-58 \%)$ were similar between the groups (see online supplementary figure E1).

\section{Primary efficacy and related endpoints}

FF/VI significantly delayed the time to the first severe asthma exacerbation relative to FF (table 2, figure 2). The adjusted probability of experiencing a severe asthma exacerbation by 52 weeks was $15.9 \%$ (95\% CI $13.5 \%$ to $18.2 \%)$ in the FF $100 \mu \mathrm{g}$ group and $12.8 \%$ (95\% CI $10.7 \%$ to $14.9 \%$ ) in the $\mathrm{FF} /$ VI $100 / 25 \mu$ group. The HR for FF/VI 100/25 $\mu \mathrm{g}$ vs FF $100 \mu \mathrm{g}$ 
Table 1 Patient demographics and baseline characteristics, intent-to-treat population

\begin{tabular}{|c|c|c|c|}
\hline & $\begin{array}{l}\mathrm{FF} 100 \mu \mathrm{g} \\
(\mathrm{N}=1010)\end{array}$ & $\begin{array}{l}\text { FF/VI } 100 / 25 \mu g \\
(\mathrm{~N}=1009)\end{array}$ & $\begin{array}{l}\text { Total } \\
(\mathrm{N}=2019)\end{array}$ \\
\hline Age, years & $42.3(16.82)$ & $41.1(17.10)$ & 41.7 (16.96) \\
\hline Female sex, $\mathrm{n}(\%)$ & $689(68)$ & $661(66)$ & $1350(67)$ \\
\hline Never smoked, n (\%) & $868(86)$ & $870(86)$ & $1738(86)$ \\
\hline Former smoker, $\mathrm{n}(\%)$ & $142(14)$ & $139(14)$ & $281(14)$ \\
\hline \multicolumn{4}{|c|}{ Number of exacerbations in last 12 months, $\mathrm{n}(\%)$} \\
\hline 0 & $1(<1)$ & 0 & $1(<1)$ \\
\hline 1 & $599(59)$ & $553(55)$ & $1152(57)$ \\
\hline 2 & $229(23)$ & $252(25)$ & $481(24)$ \\
\hline 3 & $100(10)$ & $101(10)$ & $201(10)$ \\
\hline 4 & $37(4)$ & $57(6)$ & $94(5)$ \\
\hline$>4$ & $44(4)$ & $46(5)$ & $90(4)$ \\
\hline Duration of asthma, years & $15.8(13.3)$ & $15.3(12.8)$ & $15.5(13.0)$ \\
\hline $\begin{array}{l}\text { Screening } \\
\text { prebronchodilator } \mathrm{FEV}_{1}, \mathrm{~L}\end{array}$ & $2.10(0.61)$ & $2.11(0.61)$ & $2.11(0.61)$ \\
\hline $\begin{array}{l}\text { Screening } \% \text { predicted } \\
\text { FEV }_{1}\end{array}$ & $69.0(10.41)$ & $68.8(10.62)$ & $68.9(10.52)$ \\
\hline $\begin{array}{l}\text { Screening \% reversibility } \\
\text { FEV }_{1}\end{array}$ & $24.3(12.10)$ & $24.4(12.71)$ & $24.4(12.41)$ \\
\hline $\begin{array}{l}\text { Screening absolute } \\
\text { reversibility } \mathrm{FEV}_{1}, \mathrm{~mL}\end{array}$ & $500.0(260.25)$ & $499.1(265.44)$ & $499.6(262.79)$ \\
\hline Baseline ACQ-7 score & $2.154(0.7324)$ & $2.169(0.7514)$ & \\
\hline \multicolumn{4}{|c|}{ Percentage of patients using ICS or ICS/LABA on entry } \\
\hline ICS only & $397(39)$ & $402(40)$ & \\
\hline ICS/LABA & $613(61)$ & $607(60)$ & \\
\hline
\end{tabular}

was 0.795 (95\% CI 0.642 to $0.985, \mathrm{p}=0.036$, adjusted for the interim analysis), representing a $20 \%$ risk reduction. Analysis of the PP population provided similar results: $\mathrm{HR}$ (FF/VI vs FF) was 0.722 (95\% CI 0.548 to 0.950$)$, representing a $28 \%$ risk reduction $(\mathrm{p}=0.020)$. A total of 340 patients experienced $\geq 1$ severe exacerbations; $>99 \%$ of the severe asthma exacerbations entered into the case report form were confirmed by the adjudication committee. The outcomes of subgroup analyses of treatment interactions with baseline $\mathrm{FEV}_{1}$, age, sex and region showed a statistically significant $(\mathrm{p}<0.10)$ interaction between baseline $\mathrm{FEV}_{1}$ and treatment (see online supplementary figure E2). Interactions between treatment and the remaining factors (age, sex and region) were not statistically significant.

The possibility of informative censoring was explored. The Kaplan-Meier curves for time to first severe asthma exacerbation or withdrawal due to lack of efficacy, investigator discretion or withdrawal of consent between the two treatment groups did not differ from those of the primary analysis (see online supplementary figure E3).

\section{Secondary and other efficacy endpoints}

The rate of severe asthma exacerbations per patient per year was significantly lower in the FF/VI 100/25 $\mu$ group than in the FF $100 \mu$ group (0.14 vs 0.19$)$, a reduction in rate of $25 \%(95 \%$ CI $5 \%$ to $40 \% ; \mathrm{p}=0.014)$. The number of patients experiencing $\geq 1$ on-treatment severe asthma exacerbation was also lower in the FF/VI group: 186 patients (18\%) with FF (271 exacerbations in total) versus 154 patients (15\%) with FF/VI (200 exacerbations in total). The mean duration of a severe asthma exacerbation was 11 days in both groups. Online supplementary figure E4 shows the number and duration of severe asthma exacerbations experienced by individual patients during the study.

Trough $\mathrm{FEV}_{1}$ increased over the treatment period in both the $\mathrm{FF}$ and FF/VI treatment groups (figure 3 and online supplementary figure E5). FF/VI demonstrated statistically significant improvements over $\mathrm{FF}$ in trough $\mathrm{FEV}_{1}$, with adjusted mean changes of $83-95 \mathrm{~mL}(\mathrm{p}<0.001)$.

Self-reported rescue albuterol/salbutamol use increased over the 14 days preceding an exacerbation (figure 4).

Adjusted mean changes from the baseline Asthma Control Questionnaire (ACQ7) are shown in online supplementary figure E6. Significantly greater improvements in the ACQ7 score were observed in patients receiving FF/VI compared with FF at all time points $(p<0.001$; week 12 , week 36 and endpoint). The proportion of patients with well-controlled asthma (ACQ7 score $\leq 0.75$ ) at baseline was similar in the two treatment groups (both 2\%). ORs for FF/VI versus FF at week 12 (1.49, 95\% CI 1.20 to 1.84$)$, week $36(1.49,95 \%$ CI 1.21 to 1.83$)$ and at endpoint $(1.50,95 \%$ CI 1.23 to 1.82$)$ indicated that patients in the FF/VI group were significantly more likely to be well controlled than those in the FF group (all $\mathrm{p}<0.001$ ). At endpoint, more patients in the FF/VI group than the FF group were well controlled (44\% vs 36\%).

\section{Safety assessment}

Similar proportions of patients experienced severe asthma exacerbations leading to hospitalisation with FF $(n=9,<1 \%)$ and FF/VI $(n=8,<1 \%)$. In the FF group, $26(3 \%)$ patients visited an emergency department or urgent care clinic due to a severe asthma exacerbation and 142 (14\%) made unscheduled visits to a healthcare provider. These frequencies were $22(2 \%)$ and 119 (12\%), respectively, for FF/VI. No patients were intubated due to a severe asthma exacerbation.

FF and FF/VI had similar overall safety profiles (table 3). There were 29 (3\%) on-treatment serious adverse events (SAEs) in the FF group (seven considered asthma-related by the

Table 2 Cox proportional hazards analysis of time to first severe asthma exacerbation, intent-to-treat population

\begin{tabular}{|c|c|c|}
\hline & FF $100 \mu g(N=1010)$ & FF/VI 100/25 $\mu \mathrm{g}(\mathrm{N}=1009)$ \\
\hline Adjusted \% probability of a severe asthma exacerbation by 52 weeks* & 15.9 (13.5 to 18.2$)$ & $12.8(10.7$ to 14.9$)$ \\
\hline \multicolumn{3}{|l|}{ FF/VI $100 / 25 \mu \mathrm{g}$ vs FF $100 \mu \mathrm{g}$} \\
\hline HRt & & $0.795(0.642$ to 0.985$)$ \\
\hline $\mathrm{p}$ Valuet & & 0.036 \\
\hline
\end{tabular}


Figure 2 Cox proportional hazards model cumulative incidence curve for time to first severe asthma exacerbation, intent-to-treat population. FF, fluticasone furoate; $\mathrm{VI}$, vilanterol.

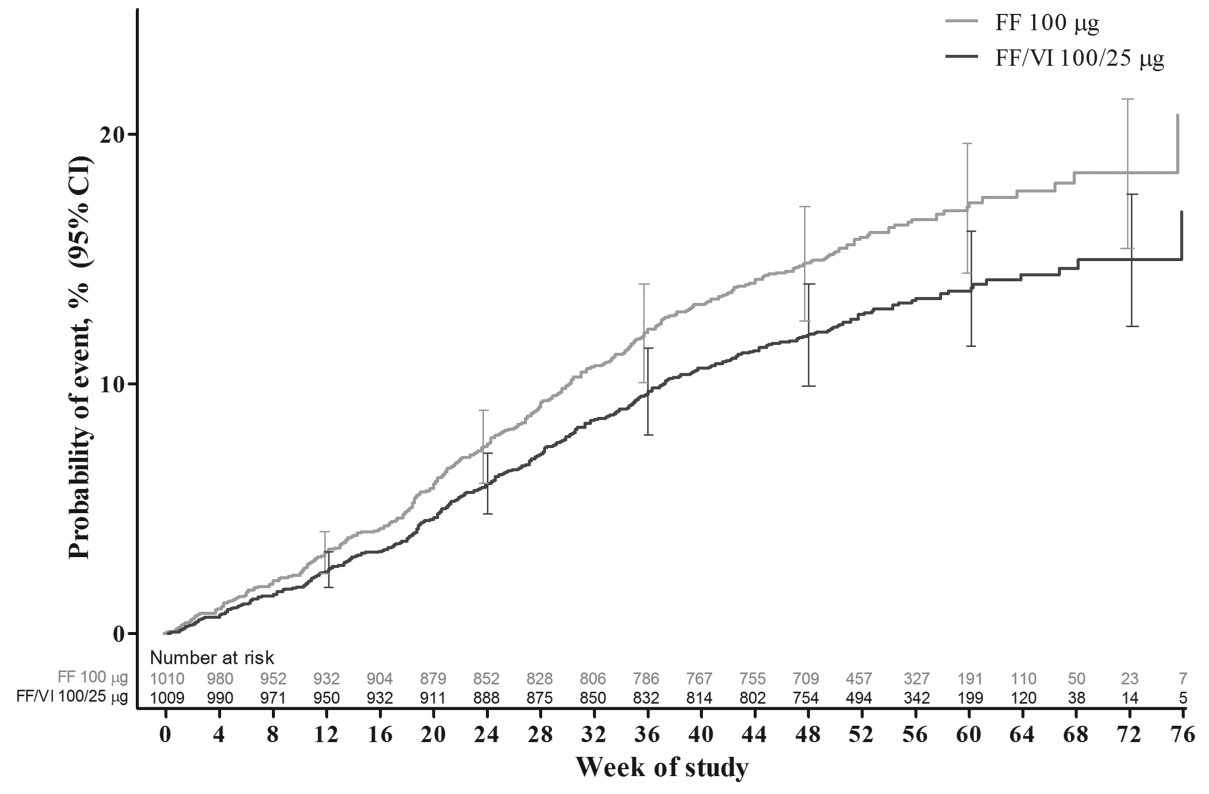

adjudication committee) and $41(4 \%)$ in the FF/VI group (10 considered asthma-related). Four on-treatment and posttreatment SAEs were deemed treatment-related, three (pleurisy, asthma, non-cardiac chest pain) in the FF group and one (tachyarrhythmia) in the FF/VI group. Three fatalities occurred: two (pneumonia, metastatic lung cancer (post-treatment)) in the FF group and one (automobile accident as passenger) in the FF/ VI group; none were deemed to be treatment-related or asthma-related by the investigators or adjudication committee.

Small but statistically significant treatment differences in change from baseline in diastolic blood pressure were observed at week $44(-0.8 \mathrm{~mm} \mathrm{Hg}, \mathrm{p}=0.022)$ and week 76/end of study $(-0.7 \mathrm{~mm} \mathrm{Hg}, \mathrm{p}=0.032)$; however, these were not considered to be clinically important. No statistically significant treatment differences in systolic blood pressure or pulse rate were observed.

\section{DISCUSSION}

This study showed that, in patients with asthma uncontrolled on ICS, FF/VI 100/25 $\mu \mathrm{g}$ once daily administered for up to 78 weeks reduced the risk of experiencing a severe asthma exacerbation by $20 \%$ and reduced the rate of severe exacerbations per patient per year by $25 \%$ compared with FF $100 \mu \mathrm{g}$ alone. FF/VI also significantly improved trough $\mathrm{FEV}_{1}$ and the number of patients achieving well-controlled asthma. FF/VI had a good safety profile without evidence of life-threatening asthma events. Reducing asthma exacerbations is considered in asthma guidelines to be the most important endpoint of future risk, and is of considerable benefit to patients because of their impact on quality of life and the high healthcare costs associated with their management. Although increasing the dose of ICS has been shown to be highly effective at reducing exacerbation risk, this approach needs to be considered in conjunction with the potential side effects of long-term use of higher doses of ICS. ${ }^{20}$
Figure 3 Adjusted mean changes from baseline in trough forced expiratory volume in $1 \mathrm{~s}(\mathrm{~L})$, intent-to-treat population. * Treatment differences $p<0.001$. FF, fluticasone furoate; LS, least squares; VI, vilanterol.

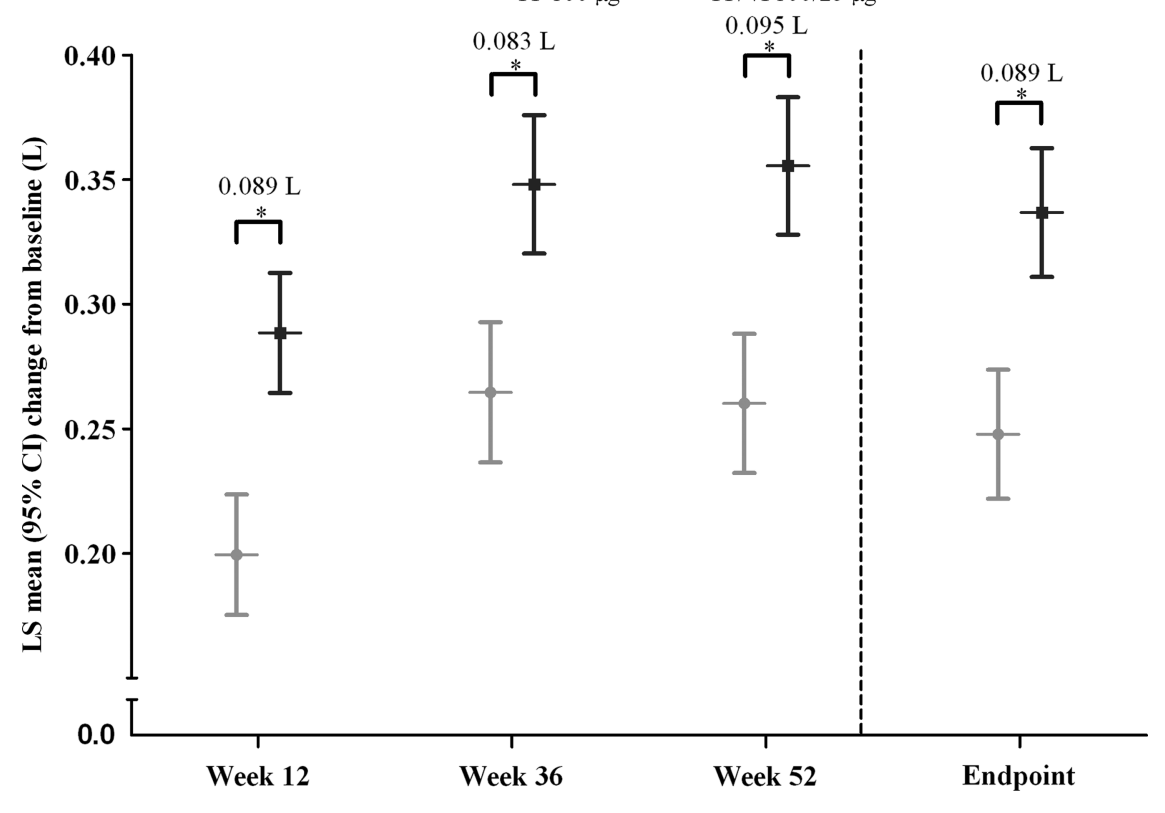


Figure 4 Mean self-reported daily rescue use (albuterol/salbutamol) 14 days before and after the onset of severe asthma exacerbation for patients who experienced $\geq 1$ or 0 severe asthma exacerbations, intent-to-treat population. *Date of onset was determined by the investigator and recorded in their clinical notes. For patients who experienced $\geq 1$ severe asthma exacerbation, all severe asthma exacerbations are included in the figure. Rescue use in patients who did not exacerbate during the study was calculated for the same duration (number of days) as each exacerbation event in exacerbating patients. For this purpose, the surrogate Day 0 for non-exacerbators was the median study day of onset for all exacerbations. FF, fluticasone furoate; $\mathrm{VI}$, vilanterol.

The results with FF/VI are consistent with those of many studies, confirming that the addition of a LABA to a medium dose of ICS improves lung function and asthma control and reduces the risk of severe asthma exacerbations including hospitalisations. ${ }^{1}{ }^{21-23}$ However, our study is the first to demonstrate this improvement with once-daily dosing. We did not compare the efficacy of FF/VI treatment with doubling the dose of FF in this cohort of patients with uncontrolled asthma, but results from studies with that design have provided clear evidence of greater clinical benefit of combination therapy compared with doubling the dose of ICS. ${ }^{24-26}$ Unlike FP and beclametasone dipropionate, for which three doses are available for use in adults, two doses of FF will be available for use in adults/adolescents. FF $100 \mu \mathrm{g}$ is suitable for use in patients who require FP 100-250 $\mu$ g twice daily and FF $200 \mu \mathrm{g}$ is suitable for patients who require FP $500 \mu \mathrm{g}$ twice daily or equivalent. Therefore, in this study, some patients will

Table 3 Most frequent $(\geq 5 \%)$ on-treatment $A E s$, intent-to-treat population

\begin{tabular}{lcc}
\hline & \multicolumn{2}{c}{ Number (\%) of patients } \\
\cline { 2 - 3 } AE (preferred term) & $\begin{array}{l}\text { FF } 100 \mu \mathrm{g} \\
(\mathrm{N}=1010)\end{array}$ & $\begin{array}{l}\mathrm{FF} / \mathrm{VI} 100 / 25 \mu \mathrm{g} \\
(\mathrm{N}=1009)\end{array}$ \\
\hline Any on-treatment AE & $652(65)$ & $636(63)$ \\
Treatment-related AE* $^{*}$ & $67(7)$ & $69(7)$ \\
AE leading to withdrawal & $19(2)$ & $16(2)$ \\
Any on-treatment SAE & $29(3)$ & $41(4)$ \\
Treatment-related SAE* & $3(<1)$ & $1(<1)$ \\
Asthma-related SAE & $7(<1)$ & $10(<1)$ \\
Headache & $179(18)$ & $188(19)$ \\
Nasopharyngitis & $131(13)$ & $155(15)$ \\
Upper respiratory tract & $93(9)$ & $73(7)$ \\
infection & & \\
Bronchitis & $74(7)$ & $59(6)$ \\
Cough & $64(6)$ & $55(5)$ \\
Oropharyngeal pain & $55(5)$ & $41(4)$ \\
Influenza & $38(4)$ & $50(5)$ \\
\hline *On-treatment and post-treatment. & \\
AE, adverse event; FF, fluticasone furoate; SAE, serious adverse event; VI, vilanterol.
\end{tabular}

have been randomised to a similar ICS dose to baseline and some may have received a reduced ICS dose.

In this study the results of secondary endpoints, including annualised rate of severe exacerbations, further support the primary endpoint. The improvements in trough $\mathrm{FEV}_{1}$ and reductions in ACQ7 scores confirm superior current asthma control with the FF/VI combination. In addition, the frequency of severe asthma exacerbations leading to hospitalisation, emergency room visit or unscheduled healthcare provider visit was similar for both FF and FF/VI. Thus, there was no indication of an increased risk of such severe events with the addition of the LABA, a finding that is consistent with several meta-analyses of studies comparing combined ICS/LABA with ICS alone. ${ }^{6} 723$

Interpreting the clinical significance of exacerbation reductions in clinical trials is easiest when the comparator is usual treatment. In this study two new treatments were compared: a new once-daily moderate dose of FF and FF combined with VI. The resultant annualised rate of severe asthma exacerbations was low in both treatment groups, 0.19 for FF (corresponding to approximately one exacerbation every 5 years per patient) and 0.14 for FF/VI (one every 7 years), despite the fact that all patients were required to have had a severe asthma exacerbation during the 1-year period prior to randomisation. The exacerbation rate observed in the FF group compares favourably with those observed in previous studies of patients uncontrolled on medium-dose ICS, in which annualised rates ranging from 0.31 to 0.35 were reported for patients receiving budesonide alone. ${ }^{25} 2728$ In two recent studies of the effect of adding salmeterol to FP on asthma exacerbation rates, ${ }^{29} 30$ rates of $0.27-0.30$ exacerbations/patient/year were reported for patients using FP monotherapy. Thus, the $25 \%$ decrease seen in this study represents a clinically useful improvement from an already very low base rate.

Regarding safety, FF and FF/VI were well tolerated and the incidence of treatment-related adverse events and all SAEs was low and similar across treatment groups. No clinically relevant treatment differences in vital signs or liver function parameters were observed. In view of the concerns regarding a possible link between LABA use and asthma-related hospitalisations and fatal events, ${ }^{4}$ no association was observed in this study of $>2000$ patients with a mean exposure of $\geq 12$ months, although we recognise that this cannot be viewed as conclusive evidence. 
The current ERS/ATS Task Force definition of severe asthma exacerbations ${ }^{17}$ was used, and an adjudication committee provided a blinded review to ensure that all severe asthma exacerbations were identified and included in the primary measure. In addition, the monitoring of rescue use preceding and during the time of each severe asthma exacerbation confirmed that exacerbations were preceded by a period of loss of asthma control, supporting the accuracy and appropriateness of recording of asthma exacerbations. ${ }^{31}$

Strengths of this study include its innovative design in which the duration was not predetermined. Instead, the study was terminated when a specified number of acute exacerbations had occurred. In addition, most patients remained in the study and received treatment for 52 weeks or more, thus permitting a reliable determination of the annualised rate of severe asthma exacerbations. In contrast, in studies of fixed duration, although nominally of 12 months' duration, mean exposures to study drugs are reduced owing to premature withdrawals, particularly for patients who experience exacerbations. However, the eventdriven design makes it difficult to compare the results of the present study with those of fixed duration. In our study, informative censoring did not occur differentially between the two treatment arms.

The dose of FF/VI (100/25 $\mu \mathrm{g})$ used in this study was selected on the basis of data from earlier phase dose-ranging studies. ${ }^{12} 13{ }^{32} \mathrm{FF} 100 \mu \mathrm{g}$ was used as the comparator, ensuring that all patients were treated with at least a mid-strength ICS throughout the study. This study was not designed to compare the effect of adding a LABA with that of increasing the dose of ICS. The study did not examine the effect of time of dosing. Finally, the study population exhibited marked bronchodilator responsivenes to a $\beta_{2}$ agonist (salbutamol) at the screening visit (approximately $500 \mathrm{~mL}$ and $22 \%$ of baseline), although only $200 \mathrm{~mL}$ and $12 \%$ was required for inclusion.

In summary, this study confirms that the combination of $\mathrm{FF} /$ VI $100 / 25 \mu \mathrm{g}$ administered once daily in the evening to adolescents and adults with moderate asthma significantly reduced the risk of severe asthma exacerbations, improved lung function and led to asthma control in a larger proportion of patients than FF $100 \mu \mathrm{g}$. Both treatments were well tolerated with similar safety profiles and a low incidence of treatment-related AEs and SAEs, and no increased risk of serious asthma-related events was seen with the addition of VI.

Acknowledgements We thank all patients and investigators involved in the study, and the members of the adjudication committee and Independent Data Monitoring Committee. Editorial support (in the form of development of a draft outline in consultation with the authors, development of a manuscript first draft in consultation with the authors, editorial suggestions to draft versions of this paper, assembling tables and figures, collating author comments, copyediting, fact checking, referencing and graphic services) was provided by lan Grieve, PhD at Gardiner-Caldwell Communications (Macclesfield, UK) and was funded by GlaxoSmithKline.

Contributors All authors, including the independent steering committee (EDB, $P M O ' B, W W B$, JLö, ERB, AW) together with authors employed by the sponsor ( $L A$, $L J, L F, J L i)$ had access to all of the data, were involved in every stage of the preparation of the paper and approved the final version. Employees of the sponsor (led by LF and JLi) performed the statistical analysis. The sponsor did not place any restriction on authors about the statements made in the final paper. All listed authors meet the criteria for authorship set forth by the International Committee for Medical Journal Editors.

Funding This study was funded by GlaxoSmithKline (study number HZA106837; ClinicalTrials.gov identifier NCT01086384).

Competing interests EDB has served as a consultant to AlkAbello, Almirall, Cephalon, Hoffman la Roche, ICON and MS Consulting Group; has been on advisory boards for Almirall, AstraZeneca, Boehringer Ingelheim, Elevation Pharma, Forest,
GlaxoSmithKline, Merck, Napp, Novartis and Nycomed; has received lecture fees from AlkAbello, AstraZeneca, Boehringer Ingelheim, Chiesi, GlaxoSmithKline, Novartis, Pfizer and Takeda; and his institution has received remuneration for participation in clinical trials sponsored by Actelion, Aeras, Almirall, AstraZeneca, Boehringer Ingelheim, Forest, GlaxoSmithKline, Hoffman La Roche, Merck, Novartis, Takeda and TEVA. PMO'B has served as a consultant to AstraZeneca, Almirall, Boehringer Ingelheim, GlaxoSmithKline and Merck; has served on advisory boards for AIM, Altair, Boehringer, GlaxoSmithKline, Medimmune and Merck; has received lecture fees from Chiesi; and has received research funding from Amgen, AstraZeneca, Asmacure, Genentech and Ono. WWB has served as a consultant to Amgen, AstraZeneca, Boehringer Ingelheim, Genentech, GlaxoSmithKline, MedImmune, Novartis and TEVA; has served on advisory boards for Altair, Amgen, Centocor, GlaxoSmithKline, Johnson \& Johnson, Merck Sharpe and Dohme and Pfizer; has received lecture fees from Merck Sharpe and Dohme; and has received research funding from AstraZeneca, Ception, GlaxoSmithKline, Medlmmune and Novartis. JLö has served as a consultant to and received lecture fees from AstraZeneca, GlaxoSmithKline, Merck Sharpe and Dohme, Novartis, and UCB Pharma; has been partly covered by some of these companies to attend previous scientific meetings including the ERS and the AAAAl; has provided expert testimony for Barr Pharmaceuticals; and has participated in clinical research studies sponsored by AstraZeneca, GlaxoSmithKline, Merck Sharpe and Dohme and Novartis. ERB has served as a consultant to AstraZeneca, Boehringer Ingelheim, Cephalon, Forest, Genentech, GlaxoSmithKline, Medlmmune, Novartis, Pfizer and Sanofi-Aventis; has received reimbursement for travel from GlaxoSmithKline; and has performed clinical trials for AstraZeneca, Boehringer Ingelheim, Centocor, Genentech, GlaxoSmithKline, Johnson \& Johnson, Merck, Novartis and Pfizer which have been administered by his employer Wake Forest University School of Medicine. AW has served as a consultant to Almirall, AstraZeneca, Chiesi, Cytos, GlaxoSmithKline, Merck Sharpe and Dohme and Novartis; and has received lecture fees and research grants from Chiesi and GlaxoSmithKline. LA, LJ, LF and JLi are employees of and hold stock in GlaxoSmithKline.

\section{Patient consent Obtained.}

Ethics approval The study was approved by local ethics review committees and was conducted in accordance with the Declaration of Helsinki, Good Clinical Practice guidelines and all applicable regulatory requirements.

Provenance and peer review Not commissioned; externally peer reviewed.

Open Access This is an Open Access article distributed in accordance with the Creative Commons Attribution Non Commercial (CC BY-NC 3.0) license, which permits others to distribute, remix, adapt, build upon this work non-commercially, and license their derivative works on different terms, provided the original work is properly cited and the use is non-commercial. See: http://creativecommons.org/ licenses/by-nc/3.0/

\section{REFERENCES}

1 Global Initiative for Asthma (GINA). Global Strategy for Asthma Management and Prevention. Updated 2011. http://www.ginasthma.org/uploads/users/files/GINA Report_2011.pdf (accessed 8 Jul 2013).

2 O'Byrne PM, Naya IP, Kallen A, et al. Increasing doses of inhaled corticosteroids compared to adding long-acting $\beta_{2}$-agonists in achieving asthma control. Chest 2008;134:1192-9.

3 Shapiro G, Lumry W, Wolfe J, et al. Combined salmeterol $50 \mu \mathrm{g}$ and fluticasone propionate $250 \mu \mathrm{g}$ in the Diskus device for the treatment of asthma. Am J Respir Crit Care Med 2000;161:527-34.

4 Nelson HS, Weiss ST, Bleecker ER, et al. The salmeterol multicenter asthma research trial. Chest 2006;129:15-26.

5 Salpeter SR, Buckley NS, Ormiston TM, et al. Meta-analysis: effect of long-acting beta-agonists on severe asthma exacerbations and asthma-related deaths. Ann Intern Med 2006;144:904-12.

6 Bateman ED, Nelson H, Bousquet J, et al. Meta-analysis: effects of adding salmeterol to inhaled corticosteroids on serious asthma-related events. Ann Intern Med 2008;149:33-42.

7 Sears MR, Ottosson A, Radner F, et al. Long-acting $\beta$-agonists: a review of formoterol safety data from asthma clinical trials. Eur Respir J 2009;33:21-32.

8 Jaeschke R, O'Byrne PM, Mejza F, et al. The safety of long-acting $\beta$-agonists among patients with asthma using inhaled corticosteroids: systematic review and metaanalysis. Am J Respir Crit Care Med 2008;178:1009-16.

9 Chowdhury BA, Seymour SM, Levenson MS. Assessing the safety of adding LABAs to inhaled corticosteroids for treating asthma. N Engl J Med 2011;364:2473-5.

10 Biggadike K, Bledsoe RK, Hassell AM, et al. X-ray crystal structure of the novel enhanced-affinity glucocorticoid agonist fluticasone furoate in the glucocorticoid receptor-ligand binding domain. J Med Chem 2008;51:3349-52.

11 Salter M, Biggadike K, Matthews JL, et al. Pharmacological properties of the enhanced-affinity glucocorticoid fluticasone furoate in vitro and in an in vivo model of respiratory inflammatory disease. Am J Physiol Lung Cell Mol Physiol 2007;293: 1660-7. 
12 Bateman ED, Bleecker ER, Lötvall J, et al. Dose effect of once-daily fluticasone furoate in persistent asthma: a randomized trial. Respir Med 2012;106:642-50.

13 Bleecker ER, Lötvall J, O'Byrne PM, et al. Efficacy of fluticasone furoate (FF) as a monotherapy and in combination with vilanterol $(\mathrm{VI})$ over 12 weeks in patients with persistent asthma. Eur Respir J 2012;40(Suppl 56):P2091.

14 Busse WW, Bleecker ER, Bateman ED, et al. Fluticasone furoate demonstrates efficacy in patients with asthma symptomatic on medium doses of inhaled corticosteroid therapy: an 8-week, randomised, placebo-controlled trial. Thorax 2012;67:35-41.

15 Boscia JA, Pudi KK, Zvarich MT, et al. Effect of once-daily fluticasone furoate/ vilanterol on 24-hour pulmonary function in patients with COPD: a randomized, three-way, incomplete block, crossover study. Clin Ther 2012;34:1655-66.e5.

16 Lötvall J, Bakke P, Bjermer L, et al. Efficacy and safety of 4 weeks' treatment with combined fluticasone furoate/vilanterol in a single inhaler given once daily in COPD: a placebo-controlled randomised trial. BMJ Open 2012;2:e000370.

17 Reddel HK, Taylor DR, Bateman ED, et al. An official American Thoracic Society/ European Respiratory Society statement: asthma control and exacerbations: standardizing endpoints for clinical asthma trials and clinical practice. Am J Respir Crit Care Med 2009;180:59-99.

18 Bateman ED, O'Byrne PM, Busse WW, et al. Effect of fluticasone furoate (FF)/ vilanterol (VI) once daily (OD) on risk of severe exacerbations in asthma. Eur Respir J 2012;40(Suppl 56):P1788.

19 National Institutes for Health (NIH). Guidelines for the diagnosis and management of asthma (EPR-3) 2007. NIH publication no 08-4051. NIH Heart, Lung and Blood Institute, 2007.

20 Irwin RS, Richardson ND. Side effects with inhaled corticosteroids: the physician's perception. Chest 2006;130(Suppl 1):41S-53S

21 Pauwels RA, Löfdahl CG, Postma DS, et al. Effect of inhaled formoterol and budesonide on exacerbations of asthma. Formoterol and Corticosteroids Establishing Therapy (FACET) International Study Group. N Engl J Med 1997;337:1405-11.
22 Bateman ED, Boushey HA, Bousquet J, et al. Can guideline-defined asthma control be achieved? The Gaining Optimal Asthma Control Study. Am J Respir Crit Care Med 2004;170:836-44.

23 Rodrigo GJ, Castro-Rodríguez JA. Safety of long-acting $\beta$ agonists for the treatment of asthma: clearing the air. Thorax 2012:67:342-9.

24 Masoli $M$, Weatherall $M$, Holt $S$, et al. Moderate dose inhaled corticosteroids plus salmeterol versus higher doses of inhaled corticosteroids in symptomatic asthma. Thorax 2005;60:730-4.

25 O'Byrne PM, Barnes PJ, Rodriguez-Roisin R, et al. Low dose inhaled budesonide and formoterol in mild persistent asthma: the OPTIMA randomized trial. Am J Respir Crit Care Med 2001;164:1892-7.

26 Shrewsbury S, Pyke S, Britton M. Meta-analysis of increased dose of inhaled steroid or addition of salmeterol in symptomatic asthma (MIASMA). BMJ 2000;320:1368-73.

27 Peters SP, Prenner BM, Mezzanotte WS, et al. Long-term safety and asthma control with budesonide/formoterol versus budesonide pressurized metered-dose inhalers. Allergy Asthma Proc 2008;29:499-516.

28 Scicchitano R, Aalbers R, Ukena D, et al. Efficacy and safety of budesonide/ formoterol single inhaler therapy versus a higher dose of budesonide in moderate to severe asthma. Curr Med Res Opin 2004;20:1403-18.

29 Kerwin E, Prazma CM, Sutton L, et al. Safety and efficacy of long-term treatment with fluticasone propionate and salmeterol via DISKUS versus fluticasone propionate alone. Clin Res Reg Aff 2011;28:14-21.

30 Katial R, Bernstein D, Prazma C, et al. Long-term treatment with fluticasone propionate (FP) and salmeterol via DISKUS (FSC) improves asthma control versus fluticasone propionate alone. Allergy Asthma Proc 2011;32:127-36.

31 Tattersfield AE, Postma DS, Barnes PJ, et al. Exacerbations of asthma: a descriptive study of 425 severe exacerbations. The FACET International Study Group. Am J Respir Crit Care Med 1999;160:594-9.

32 Busse WW, Bleecker ER, Bateman ED, et al. Fluticasone furoate demonstrates efficacy in patients with asthma symptomatic on medium doses of inhaled corticosteroid therapy: an 8-week, randomised, placebo-controlled trial. Thorax 2011:67:35-41. 